\title{
SUPPLY AND DEMAND
}

Dear Reader,

A "window of opportunities" is the modern way of describing a favourable set of conditions that promises results. The large engine sector is currently experiencing such a window. A sharp fall in gas prices and increasingly high costs caused by tighter emissions legislation for diesel engines are now making gas engines extremely attractive. As a consequence, we are seeing a rise in demand for gas engines, and engine manufacturers are reacting by ramping up development capacities and expanding their product portfolio.

By contrast, the window of opportunities for electromobility seems to remain tightly shut for the time being. Limited utility value and high costs are making electric cars less attractive for the end customer than vehicles with an internal combustion engine. There will, of course, be further developments that are bound to improve these aspects of the drive system. But the physical and chemical limitations mean that progress is likely to be insufficient. The favourable conditions for the development of customer-friendly products are not yet available, and the result is a lack of market demand. In order to take electromobility out of the doldrums, some European governments have introduced generous financial incentives for the purchase of an electric vehicle. But that will not offer a sustainable solution to the problem if the time for electromobility is really not yet ripe. Of course, temporary government funding can often kick-start a market. But when it comes to electromobility, that would mean supporting sales of electric vehicles for a long time with high sums of money in order to generate an artificial demand. That no longer has anything to do with the healthy interaction between supply and demand. What do you think? You can let me know by sending me e-mail to Richard.Backhaus@springer.com.

King regards,

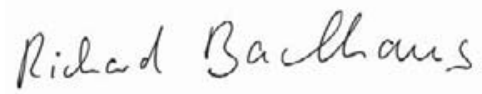

RICHARD BACKHAUS, Vice-Editor in Chief Wiesbaden, 15 November 2012

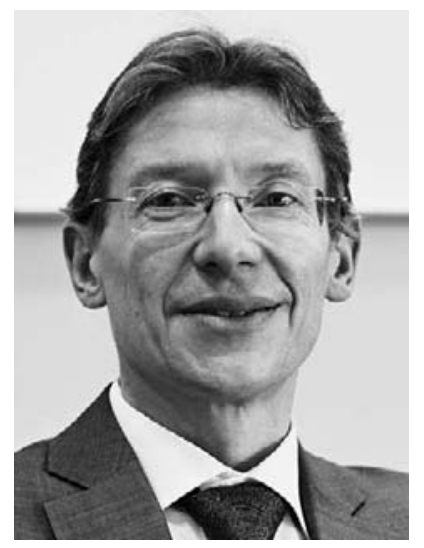

